of students who are on the whole well prepared but who lack in some particular sufficiently large to merit consideration? Is it fair to them, or necessary in the effort to secure and maintain proper standards, to deny them medical matriculation, or to require them to spend another year on premedical work before they are accepted? Are such students able to pursue the study of medicine successfully? Can provision be made that will at the same time be fair to them, fair to those who enter with all requirements satisfied, and operable without abuse?

\section{HERPES ZOSTER AND CHICKENPOX}

\section{BENJAMIN GOLDBERG, M.D.} AND

FRANCIS D. FRANCIS, A.B., M.D.

Resident Physician and Attending Physician, Respectively, Cook County Hospital

CHICAGO

During the month of January, 1918, at the Cook County Hospital, there were admitted three patients who had herpes zoster with a simultaneous chickenpox. This was of such unusual occurrence that the literature was consulted. Head, ${ }^{1}$ in 1900 , described a patient, a boy, who developed a herpes zoster on the fifth dorsal region which in twenty-four hours was followed by a typical chickenpox eruption. Corlett, ${ }^{2}$ in 1905 , cited four such occurrences, in adults aged, respectively, $40,44,48$ and 70 years. Bokay, ${ }^{3}$ in a period of time extending from 1891 to 1909 , observed nine different cases of herpes zoster, of various locations, which in the members of the families exposed only to the herpes, after incubation periods of intervals varying from eight to twenty days, resulted in the production of fifteen cases of chickenpox in their respective families.

Richardson ${ }^{4}$ reports that in a convalescent scarlet fever ward, one of the patients developed a profuse herpes zoster of lower dorsal and upper lumbar distribution. The patient was not isolated, but was nursed in the main ward. Exactly two weeks following, chickenpox broke out in the ward, three patients being affected, and all three had been in the hospital longer than three weeks, the time being thirty, thirtytwo and forty days, respectively. All of these patients were isolated, and no more cases of cross infection resulted.

\section{REPORT OF CASES}

CASE 1.-A. O., man, aged 53, single, cook, admitted, Jan. 19, 1918, complained of a rash on the body, and of itching. About one week before, the patient had noticed a skin eruption at the side of his chest. This was of a "raw beef" color, and "burned" or tingled. Numerots small blisters formed on it. About three days following the onset, he noticed a series of small pimples and blisters. They were not accompanied by any subjective symptoms, and appeared over the face and trunk. The patient had had typhoid at the age of 25 . Chancre and gonorrhea were admitted. He was addicted to the use of alcohol.

On the skin in the area composing the segment in the eighth to the ninth left dorsal region, terminating at the

1. Head, Henry: Herpes Zoster, or Zona, in Allbutt: System of Medicine, New York, $1900,8,630$.

2. Corlett, W.: Varicella Accompanying Herpes Zoster, Jour. Cutan. Dis., 1905, 23, 289-293.

3. Bokay, J.: Etiologic Relation between Varicella and Herpes Zoster, Orvosi hetil., 1909, Series 3, 1, 736-738.

4. Richardson, G.: Relation between Herpes Zoster and Chicken Pox, Lanch', London, $1913, \mathbf{2}, 1732$ midline anteriorly and posteriorly, was an irregular patchy area of erythema, surrounded by vesicles in groups, and crusts, in an apparent stage of recrudescence. Over the face and trunk there were discrete, vesicular, pustular and crusted lesions, in various stages; there was an occasional lesion on the legs and arms. The fauces, pharynx and palate also showed a discrete distribution of vesicles and papules. The teeth were carious, and the patient had pyorrhea alveolaris. There was bilateral potential inguinal hernia. Otherwise the examination was negative.

The blood count revealed: leukocytes, 9,400 ; erythrocytes, $5,200,000$. The Wassermann test was negative. A culture in 1 per cent. glucose broth and on Petri plates was sterile after ninety-six hours. The spinal fluid pressure was not increased. There were 6 cells per cubic millimeter. The Ross-Jones test for globulin was negative. Culture in 1 per cent. glucose broth and on blood agar plates was sterile after ninety-six hours. The urine was negative.

C.ASE 2.-A. G., man, aged 38, married, laborer in a biscuit factory, admitted, Jan. 31, 1918, complained of pain and swelling of the right forehead and eye, with blistering. The patient stated that six days before he had developed a severe pain in his right eye, which became swollen. Next day there was a "burning or itching" feeling in the right forehead. This continued. A crop of blisters appeared which had persisted since. Two days following the onset he noticed a small eruption of pimples on his body; no subjective symptoms preceded this. He had had gonorrhea one year before; otherwise the previous history was negative.

Over the right half of the forehead, well demarcated at the midline, extending back to the hairline and down over the eyebrow, laterally to the upper temporal region, was an area of diffuse erythema, surrounded by large, irregular blebs. The right eye showed chemosis of the lids, with a slight superficial injection of the conjunctiva. Over the body, especially the thorax and abdomen, there was a discrete sprinkling of macules, papules, vesicles and pustules, with occasional crusting, in different stages. Very few of these lesions were seen on the extremities, and none on the face. There were also found adenopathy, posterior cervical, epitrochlear and inguinal; marked pyorrhea alveolaris, and hypertrophiert injected tonsils.

The blood count revealed: leukocytes, 10,200; erythrocytes, $4.800,000$. The Wassermann test was negative. A culture in 1 per cent. glucose broth and on plates was sterile after ninety-six hours. The spinal fuid was clear. There were 4 cells per cubic millimeter. The Ross-Jones test for globulin was negative. A culture in 1 per cent. glucose broth and on blood agar plates was sterile after ninety-six hours. The urine was negative.

CASE 3.-T. P., man, aged 27, single, sailor, admitted, Jan. 3. 1918, complained of pain and swelling of the right eye. About two weeks before he began to have a sharp pain over the right eyebrow. This pain was not very severe. Two days before, the eye became swollen so that the patient could not open it, and at the same time numerous blisters appeared on the forehead over it. Previous illnesses were denied.

Over the right side of the forehead, extending down to the lower eyelid, and laterally, and midline to a line on a level with the external canthus of the right eye, was a sharply defined elevated reddish area, slightly edematous, covered with vesicles and blebs. The eyelids were markedly chemotic, and could not be opened; a yellowish serum exuded between the lids. The neck, chest, abdomen and back showed a sprinkling of papules and vesicles, the vesicles being clear and having a red areola. Several of the teeth were carious, but otherwise were negative. The urine was negative.

\section{COM MENT}

Etiologically, von Bärensprung, ${ }^{5}$ in 1863, first demonstrated herpes zoster as being an acute inflammatory condition of the ganglion corresponding to the region

5. Von Bärensprung: Fernere Beiträge zur Kenntniss der Zosters, Ann. d. char. Krankenh., Berlin, 1863, 11, 96. 
affected. Head and Campbell, ${ }^{6}$ in 1900 , pathologically demonstrated the presence of micro-organisms in the nerve radicles involved, and contended that herpes zoster was an acute specific disease. This was later experimentally proved by Rosenow and Oftedahl, ${ }^{7}$ in their work on specific streptococci selection, by isolating streptococci from tonsils, pyorrheal abscesses, sputum and spinal fluid in man with herpes, and producing herpes, with corresponding ganglionic lesions, by animal inoculation with these strains of organisms.

As to chickenpox, nothing has ever been definitely determined etiologically. Tyzzer, ${ }^{8}$ in a histopathologic study of chickenpox vesicles, found certain bodies enclosed in the nuclei and cytoplasm of the cells involved. These he considered typical of chickenpox, but he was unable to produce new lesions by their inoculation, and had to consider them as nonparasitic. Keysselitz and Mayer ${ }^{9}$ believed that the inclusion bodies of chickenpox were analogous to cytoryctes and that they were not in themselves definitely parasites, but contained the infective virus.

Very little else has been discovered.

\section{COLORIMETRIC DETERMINATION OF REACTION OF BACTERIOLOGIC MEDIUMS AND OTHER FLUIDS}

\author{
GEORGE D. BARNETT, M.D. \\ Passed Assistant Surgeon, U. S. Naval Reserve force \\ AND \\ HERBERT S. CHAPMAN, M.D. \\ Assistant Surgeon, U. S. Navy \\ SAN FRANCISCO
}

- The colorimetric methods in common use for determining and adjusting the reaction of bacteriologic mediums and other fluids involve the use of standard solutions of known hydrogen ion concentration. A variety of such solutions has been described, and they are readily prepared by any one having a moderate chemical equipment and ability. Just now, however, many men with comparatively little chemical training are confronted with problems of this nature, and the method here described has therefore been devised to accomplish a fairly accurate determination of hydrogen ion concentration without the necessity of preparing standard solutions or of depending on those prepared by others. We are here concerned only with reactions lying between 7.0 and 8.0 , and only phenolsulphonephthalein has been used as an indicator. Other indicators and other ranges of acidity will be investigated later.

In this method use is made of the principle of superimposing the two extreme colors of the indicator, as used by Clark and Lubs, ${ }^{1}$ following Salm, ${ }^{2}$ in determining the so-called half-transformation points of indicators. Within the range of its transition from red to yellow, we may regard the observed color of a

6. Head and Camplell:: The Pathology of Herpes Zoster and Its Bearing on Sensory Localization, Brain, London, 1900, 23, 353 .

aring on Sensory Localization, Brain, London, 7. Rosenow, E. C., and Oftedahl, S.: The Etiology and Experimental
Production of Herpes Zoster, THE Jour at A. M. A., June, 12, 1915, Production of Herpes Zoster, The Jour N

p. 1968; Jour. Infect. Dis., 1916, 18, 477 . 8. Tyzzer: Histology
Research, 1906, 14, 361 .

Research, 1906, 14, 361. 9. Keysselitz and Mayer: Zur Aetiologie der Varicellen, Arch. f. Protistenk, Jena, 1909, 14, 113.

1. Clark and Lubs: Jour. Bacteriol., 1917, 2, 109, 191.

2. Salm: Ztschr. f. phys. Chem., 1906, 57, 471 phenolsulphonephthalein solution as composed of a definite amount of red plus a definite amourit of yellow, and such a color may be exactly duplicated by superimposing the extreme red and the extreme yellow of the indicator in proper-concentrations. Thus, if to one test tube we add 5 c.c. of dilute acid, and to another similar tube 5 c.c. of dilute alkali, and to each add 5 drops of phenolsulphonephthalein solution, a bright yellow will be produced in the first tube and a bright red in the other. But if we look toward the light through both tubes, a color will be observed that is half way between the yellow and the red. In fact, it will be identical with the color produced by 10 drops of the phenolsulphonephthalein solution in 5 c.c. of a standard solution having a $p_{\mathrm{H}}$ of 7.9. This is the half transformation point, and is a definite constant for this indicator. But if instead of using equal amounts of indicator in each of the two tubes we vary the partition of the 10 drops of indicator between them, then by superimposing each pair and viewing them by transmitted light, a series of colors will be produced which will cover the range of usefulness of the indicator; and once such a series is "calibrated" against solutions of known hydrogen ion concentration, it may be used as a standard series for the determination of unknown reactions.

Results obtained by such a procedure in the case of phenolsulphonephthalein, comparison being made with phosphate-solutions prepared according to Sörensen," are as shown in the accompanying table.

\begin{tabular}{ccc} 
RESULTS & WITH & PHENOLSULPHONEPHTHALEIN \\
$\begin{array}{c}\text { Acid Tubes } \\
\text { Phenolsulphonephthalein } \\
\text { Solution, Drops }\end{array}$ & $\begin{array}{c}\text { Alkali Tubes } \\
\text { Phenolsuiphonephthalein } \\
\text { Solution, Drops }\end{array}$ \\
9 & $\mathbf{1}$ & $0 \mathrm{pH}$ \\
8 & 2 & 6.9 \\
7 & 3 & 7.5 \\
6 & 4 & 7.7 \\
5 & 5 & 7.9 \\
4 & 6 & 8.1 \\
\hline
\end{tabular}

\section{OUTLINE OF METHOD}

Apparatus and Chemicals Required.-1. Clean test tubes. These must be of approximately the same diameter. An equal volume of water is measured into a number of tubes, and fifteen or twenty are selected for use in which the water stands at about the same level.

\section{A 5 c.c. pipet.}

3. A medicine dropper drawn out to a fairly fine point.

\section{A buret.}

5. An indicator solution. A convenient solution (0.01 per cent.) of phenolsulphonephthalein is prepared by diluting 1 c.c. of the usual solution used for kidney function tests ( 1 c.c. $=6 \mathrm{mg}$.) to 60 c.c. with distilled water. No accuracy is necessary, provided the same solution is used throughout.

6. Roughly normal and twentieth normal sodium hydroxid.

7. Hydrochloric or sulphuric acid.

Preparation of Standard Color Series.-Twelve test tubes are placed in two rows of six. Into each tube of one row 5 c.c. of dilute alkali are placed. (The twentieth-normal sodium hydroxid may be used, or any solution sufficiently alkaline to bring out the maximum red color of the indicator.) Into each tube of the other row, 5 c.c. of very dilute acid are placed (One

3. Sörensen and Palitzsch: Biochem. Ztschr., 1910, 24, 387. 